\title{
Branch architecture QTL for Pinus elliottii var. elliottii $\times$ Pinus caribaea var. hondurensis hybrids
}

\author{
Mervyn Shepherd ${ }^{\mathrm{a}^{*}}$, Michael Cross ${ }^{\mathrm{a}}$, Mark J. Dieters $^{\mathrm{b}}$ and Robert Henry ${ }^{\mathrm{a}}$ \\ ${ }^{a}$ Cooperative Research Centre for Sustainable Production Forestry, Centre for Plant Conservation Genetics, Southern Cross University, \\ PO Box 157, Lismore, NSW, Australia \\ ${ }^{\mathrm{b}}$ Cooperative Research Centre for Sustainable Production Forestry, Queensland Forestry Research Institute, Gympie, QLD, Australia
}

(Received 5 July 2001; accepted 11 February 2002)

\begin{abstract}
Putative quantitative trait loci (QTL) of moderate, additive effect were identified for branch diameter, average number of branches per whorl per tree, average whorl spacing and regularity of whorl spacing in a single Pinus elliottii var. elliottii $\times$ P. caribaea var. hondurensis family. There was no evidence of additive $\times$ additive epistasis or pleiotropy. No marker-trait associations were detected for the average branch angle per whorl per tree. The detection of gene effects that were seemingly larger but less numerous than those expected for traits with low to moderate heritabilities was attributed to bias in the estimation of QTL magnitude and limited power to detect QTL due to a small sample size. Branch architecture traits exhibited considerable variation within the family with ranges of 4-6 standard deviations (SD) and tended to be less variable than height and diameter. Branching characters were largely independent of one another as well as growth, form and wood density properties. Branching characters other than branch angle were not influenced by macro-environmental factors.
\end{abstract}

genetic mapping / branch angle / branch diameter / whorl spacing / whorl regularity

Résumé - QTL concernant l'architecture de la branchaison chez les hybrides entre Pinus elliottii var. elliottii Pinus caribaea var. hondurensi. On a identifié des QTL qui semblent avoir un effet modéré et additif pour les caractères : (1) diamètre des branches ; nombre moyen de branches par verticille ; espacement moyen entre verticilles et régularité de cet espacement dans une famille de Pinus elliottii var. elliottii $\times$ Pinus caribaea var. hondurensi. Aucune épistasie additif $\times$ additif ou pléiotropie n'a pu être mise en évidence. Il n'a pas été possible non plus de trouver un marqueur associé au caractère angle des branches au niveau verticille et arbre. Les effets des gènes qui ont été détectés peuvent sembler plus importants, et le nombre de gènes moins élévé que ce qu'on pourrait attendre pour des caractères à héritabilité faible à moyenne. Ceci s'explique par la faible dimension de l'échantillon qui induit un biais dans l'estimation de l'effet QTL et limite le pouvoir de détection de ces QTL. La variabilité intra-famille des caractères de branchaison est considérable, avec une amplitude de 4-6 écarts-types ; elle tend à être moins élevée que celle de la hauteur et du diamètre. Ces caractères de la branchaison sont largement indépendants les uns des autres, mais aussi des caractères forme, densité du bois et vigueur. À l'exception de l'angle des branches, ils ne sont pas influencés par les facteurs macro-environnementaux.

cartographie génétique / angle des branches / diamètre des branches / espacement des verticilles / régularité des verticilles

\section{INTRODUCTION}

Some of the most detailed genetic models for commercial traits in forestry have been provided by mapping their underlying quantitative trait loci (QTL). The need to understand quantitative traits in tree species has driven QTL studies in a range of characters important to forestry, including growth and vigour, wood properties, foliar oil composition, vegetative propagation traits, branch habit characteristics and physiological traits $[1,5,9,13,14,26,32]$.

Branching architecture in trees is important for wood quantity. It defines the structural basis for photosynthesis surfaces and hence tree productivity [11]. Branching characteristics also influence wood quality as the commercial value of timber may be reduced because knots lower the strength of structural timbers. Knot size is determined by the angle and

* Correspondence and reprints

Tel.: 612 66203412; fax: 612 66222080; e-mail: mshepher@scu.edu.au 
the diameter of the branch [22]. Changing tree form and branching may be the fastest way to improve wood properties because of the higher heritabilities of these characters compared to most wood chemistry characters and their ease of measurement [42]. Knowledge of the genetics underlying tree branching architecture would allow breeders to increase productivity [39].

Exotic Pinus spp. plantations comprise around 130000 ha of the plantation estate in Queensland. Of this, around 100000 ha may be considered most suited to an interspecific hybrid between P. elliottii Engelm var. elliottii Little and Dorman (PEE) and P. caribaea Morelet var. hondurensis Barrett and Golfari (PCH) [16]. The hybrid is the taxon of choice as it combines favourable characteristics from the parents, providing superior growth and form across a range of sites in Queensland [10, 28, 37]. Hybrid pine wood is primarily used for structural timbers, veneer and plywood products [24].

The parents of the hybrid differ markedly in their growth patterns. The $\mathrm{PCH}$ parent generally grows fastest as it grows throughout the year, whereas PEE has a distinct period of dormancy followed by a vigorous burst of growth early in the season [35]. As a consequence of their different growth patterns, the two species also have distinctive branching habits $[9,35]$. PCH tends to have more regular internode distances and lighter, flatter branches than PEE. PCH also typically has better stem straightness and fewer ramicorns than PEE.

Despite it potential importance to wood properties, little is known about the extent and causes of variation in branch characters in PEE $\times \mathrm{PCH}$ hybrids. From the single detailed study carried out to date, on a single second generation hybrid family derived from a self pollination of an interspecific $F_{1}$, compared with height and diameter, branch angle had a similar low coefficient of variation, branch diameter and the number of branches per whorl were moderate, whereas the average number of branches per whorl and regularity of whorl spacing was high [9]. Of those traits that were measured, most indicated continuous, approximately normal distributions except for branch angle, which was tri-modal. This indicates that some branching traits may exhibit relatively high levels of within family variability, that they are largely quantitative but that there may also be large gene effect segregating for some traits in some families.

Evidence from studies of pure species populations of pines indicates that low to moderate amounts of additive genetic control are typical for branching characteristics as narrow sense heritabilities typically range from 0.10 to 0.49 , with branch angle amongst the more heritable characters [22, 23, 42]. There is also a general acceptance that the environment is a large factor in determining variability in branching characters and also that in some cases, nonadditive genetic variation can be significant (p. 170 [42]). However, caution is needed in inferring results from pure species to interspecific hybrids. Hybrids offer unique combinations of genes and issues of incompatibility and differences in the relative importance of dominance and nonallelic interactions arise when comparing hybrids and pure species taxa $[5,27,38]$. Our best indications of the types of genetic control involved in plant architecture may come from QTL studies of interspecific hybrids involving inbred crops. There is strong evidence from a number of independent studies that there are relatively few genes, often of large effect, responsible for the genetic control of traits describing plant and inflorescence architecture in wide hybrids $[4,25]$. At present, however, it is unclear whether the genetic control of branch architecture in interspecific pine hybrids will follow a typical quantitative model as with many of the characters of interest to the tree breeder, or, whether the variation will be accounted for by few genes of large magnitude, as has been found for morphological characters defining plant architecture in interspecific crop hybrids.

In this paper we report preliminary identification of QTL for branching architecture in hybrid pines. We sought to understand: (1) the extent and type of genetic control; (2) juvenile-mature correlations; (3) the effect of environment and (4) the relationship of branching traits with other commercial traits. Site effects and phenotypic correlations amongst branching architecture, growth, form, wood density and bark thickness were investigated. Genetic correlations amongst branching architecture traits and with other commercial traits were investigated through co-localization of QTL. We discuss implications for breeding and further experimentation.

\section{METHODS}

\subsection{Population and field experiment}

The study is based on a single interspecific $\mathrm{F}_{1}$ hybrid family from the cross of a PEE seed parent (1EE1-102) and a $\mathrm{PCH}$ pollen donor (1CH1-063). The family was planted out within a hybrid progeny trial with a randomised plot design at two sites within south-east Queensland during March 1994. A total of 89 trees, 60 at the Beerburrum and 29 at the Tuan site were available for phenotypic assessments. Trees were planted in five-tree line plots with a spacing of $5 \times 2.1 \mathrm{~m}$ at Beerburrum and $4.5 \times 2.4 \mathrm{~m}$ at Tuan. The sites were chosen to represent extremes for the target area for which the hybrid is planted in south-east Queensland. The Tuan site is generally considered less productive, with trees of lower girth and form, due to its lower rainfall (1337 $\mathrm{mm}$ versus $1665 \mathrm{~mm}$ ) and poorer soil (Lateritic podzolic versus deep Red earth) $[9,28]$. A further four individuals from a second controlled cross of the same parents were included in the population used to generate a genetic map. These seedlings, however, were too young for phenotypic assessments.

\subsection{Phenotypic assessments}

Five branch architecture traits were assessed over 3 days in October 2000 similar to those described in Dale 1994.

1. Average branch angle (AVBRA): the mean angle from horizontal of all branches (excluding ramicorns) between breast height $(1.3 \mathrm{~m})$ and up to 6 meters but less than 7 whorls from the base of the 
tree. The angle was measured using an unclinometer (Suunto) placed at the base of the underside of a branch and reading the angle from horizontal.

2. Average number of branches per whorl (AVBRN): the mean of the number of branches per whorl for whorls defined above.

3. Average branch diameter (AVBRD): the mean diameter at the base of all branches in all whorls defined above. Diameter was measured to the closest millimetre using a micrometer.

4. Average whorl spacing (AVWS): the average distance between major branch whorls as defined above. The height of each whorl was measured with height sticks and the distance between whorls derived by subtraction.

5. Regularity of whorl spacing (CVWS): defined as the coefficient of variation for whorl spacing. This was calculated for each tree as the within tree standard deviation for whorl spacing divided by the mean whorl spacing and expressed as a percentage.

Variables for analysis were derived as an average for each tree over all whorls measured except for AVWS and CVWS.

Three trunk form traits were also assessed.

1. Stem class (SC): assessed subjectively on a scale of 1-6 using the following criteria:

$1=$ Bend $>$ tree diameter; $2=$ bend $=$ tree diameter; $3=$ bend $=$ $3 / 4$ tree diameter; $4=$ bend $=1 / 2$ tree diameter; $5=$ bend $=1 / 4$ tree diameter; $6=$ perfectly straight.

2. Ramicorns (RAM): the number of distinctively large, steep angled branches observed per tree.

3. Double leaders (DL): recorded as (0) for trees with a single main leader and (1) for trees with two equal main leaders.

Bark thickness was measured at four positions around the trunk at breast height using a bark gauge (Suunto P/L). An average of the four bark thickness measures (AVBT) was analysed. A further derived variable, relative bark thickness (RBT) was calculated for the proportion of bark in the trunk basal area. Trunk basal area was calculated from diameter at breast height measures:

$$
\mathrm{RBT}=\left[(\mathrm{OBDBH})^{2}-(\mathrm{UBDBH})^{2}\right] /(\mathrm{OBDBH})^{2} .
$$

Growth was assessed at 78 months and 84 months of age at the Beerburrum and Tuan sites respectively. Trunk height (HT) was measured using height sticks. Overbark diameter at breast height $(1.3 \mathrm{~m})$ $(\mathrm{OBDBH})$ was measured using a circumference tape. Under bark diameter at breast height (UBDBH) was derived by subtracting $2 \times$ AVBT from OBDBH for each tree.

\subsection{Descriptive statistics and phenotypic correlations}

Traits which were believed to conform to requirements for parametric tests (all traits except DL, RAM and SC were tested for normality (Kolmogorov-Smirnov'KS test) [40]. Site means were compared by t-tests for traits conforming with approximately normal distributions or by a Mann-Whitney test or in a contingency table (DL) for non-normal traits. All tests were carried out using the
Basic Statistics or Nonparametric modules of Statistica v4 (Statsoft, Tulsa, OK).

Site adjusted phenotypic correlations were determined by regressing out site and plot effects and analysing correlations amongst residuals using the multiple regression and basic statistics modules of Statistica. An experiment-wise error level $(\alpha=0.05)$ was applied to correlations using Bonferroni's method [30].

\subsection{Genetic maps}

A pseudotestcross strategy was used to generate a framework genetic map for each parent based on a sample of $93 \mathrm{~F}_{1}$ hybrid progeny [15]. Details of genetic map construction are given in Shepherd et al. (in review). Briefly, DNA was prepared from foliage from 93 progeny according to Graham et al. (1994). Amplified fragment length polymorphic (AFLP) markers were generated based on the methodology described in Remington et al. (1999). A total of 299 AFLP markers were identified that segregated in the mapping population in a testcross configuration. Twelve microsatellite markers that transferred from related hard pines and were found to segregate in the mapping population were also included in the linkage analysis [34]. Framework maps were constructed using MapMaker Experimental v3 (MME) and based only on those markers in a testcross configuration [20,21]. Markers whose parental genotype indicated a testcross mating type yet segregated with a $3: 1$ ratio in the $F_{1}$ progeny were excluded from analysis. Global grouping threshold was set at $\log$ of the odds (LOD) $550 \mathrm{cM}(\mathrm{K})$. Best order maps for each linkage group were established first by using the ripple command. A maximum of eight markers per linkage group were rippled simultaneously. Those groups for which the best order was not greater than a LOD 2 relative to the next alternative order were retested after dropping one or more markers. Markers were dropped on the basis of a quality rating and whether they tended to swap order, until an order with an interval support greater than LOD 2 was achieved. The order was then retested by "rippling". With larger groups of greater than eight markers, a subset of high quality, well-spaced markers was chosen from the best order as an initial start group. Other markers were then added to the framework using the "build" command using a threshold LOD linkage of 2 . The final order was retested, rippling eight markers or less at a time. The number of markers in each framework map and the map coverage is summarised in table I.

\subsection{Composite interval mapping}

Marker-trait associations were investigated using composite interval mapping (CIM) with a site co-variate in QTLCartographer v1.14 for the PC [3]. Background markers were selected using the FB option in the Srmapqtl module. Experiment-wise error rates were determined empirically using 1000 permutations tests [8]. CIM was carried out using the default criteria in Zmapqtl module of QTLCartographer. QTL are reported where their significance exceeds an experiment-wise error level of 0.05. Two-locus epistatic

Table I. Genome coverage for framework maps of individual PEE and PCH trees.

\begin{tabular}{lcccccc}
\hline Species & No. of groups & No of markers & Total length of groups cM (Kosambi) & Av. spacing & Map length $^{2} \mathrm{cM}_{(\text {Kosambi) }}$ & $\%$ Genome coverage \\
\hline P. elliottii & 23 & 78 & 836 & 15.2 & 1170 \\
P. caribaea & 27 & 109 & 1283 & 15.7 & 1658 \\
\hline
\end{tabular}

${ }^{1}$ Average framework marker spacing = sum of length of all linkage groups upon the number of framework marker intervals minus the number of linkage groups [29].

${ }^{2}$ Map length determined as per Kubisiak et al. (1995) i.e. total length of groups adjusted for 24 true telomeric ends.

Based on a genome size of $1700 \mathrm{cM}$ (Kosambi) for P. taeda determined by Remington et al. (1999). 
interactions (additive $\times$ additive) were investigated amongst markers significantly linked to QTL by testing for significance of interaction effect using a fixed effect model in the ANOVA module of Statistica [5].

\subsection{Single-marker tests}

A set of 320 markers from either parent which constituted the set of markers used to develop framework maps for the parents were used in single marker tests with RAM, DL and SC. These markers were all mapped in a backcross configuration and although they did not necessarily have 1:1 segregation they did not fit 3:1. $2 \times 2$ contingency table tests were used to test for associations with each marker for the traits using the Basic Statistics module of Statistica. An experiment-wise error level 0.05 was applied to each trait using the sequential Bonferroni method which declared the most significant association significant if the pair-wise $P$-value was less than $1.56 \mathrm{E}-4$

\section{RESULTS}

\subsection{Frequency distributions and influence of site upon traits}

All traits had approximately normal distributions except for SC, RAM and DL (table II). RAM, SC and DL variables were not expected to meet requirements for parametric tests and were analysed by non-parametric tests. Traits varied in their ranges, from 4.4 SD for AVBRN to 7.3 SD for HT. Site significantly affected HT, OBDBH, BD, AVBT, SC, RBT and AVBRA. Tuan is regarded as a poor site compared to Beerburrum and tends to produce trees with poorer form and growth. The significantly higher averages for HT and DBH traits at Tuan in this study probably were a result of the differ- ence in age when the two sites were assessed. Hence, in this study the site effect was confounded with an age effect for growth traits. The poorer form at Tuan was evident in the lower SC ratings for this site; however, it was not clear why Tuan should produce trees with thicker bark or more steeply angled branches. Higher average wood density values for the Tuan site were consistent with the expected slower growth rate for this site and a latitudinal effect which causes a higher proportion of latewood (higher density) as pines are grown closer to the equator at the same elevation (Harding, pers. comm.; [41]).

\subsection{Phenotypic correlations}

Overbark diameter at breast height was highly $(\mathrm{r}>0.7)$ positively correlated with UBDBH (table III). Tree height was moderately $(0.3>r>0.7)$ positively correlated with both OBDBH and UBDBH. Average bark thickness was moderately positively correlated with RBT, OBDBH, UBDBH, and AVBRA. Relative bark thickness was moderately negatively correlated with UBDBH. Average whorl spacing was moderately positively correlated with AVBRD. AVBRD was moderately positively correlated with OBDBH and UBDBH.

\subsection{Composite interval mapping}

A total of 16 putative QTL were detected using CIM with a site co-variate in QTLCartographer (table IV). Traits where more than one putative QTL was detected per parent were tested for epistatic interactions. No significant interactions (additive $\times$ additive) effects were detected for any traits (data not shown).

Table II. Descriptive statistics and test for site effects for growth, form, branch architecture and bark thickness traits in a hybrid pine family at two sites, Tuan and Beerburrum.

\begin{tabular}{|c|c|c|c|c|c|c|c|}
\hline Variable & $\begin{array}{r}\text { Overall } \\
\text { Mean } \pm \text { SD }\end{array}$ & $\begin{array}{r}\text { Range } \\
\text { (SD) }\end{array}$ & $\begin{array}{l}\text { KS Test } \\
(\text { normal }= \\
P \text {-value }>0.05 \text { ) }\end{array}$ & $\begin{array}{r}\text { Tuan }(\mathrm{n}=29) \\
\text { Mean } \pm \text { SD }\end{array}$ & $\begin{array}{r}\text { Beerburrum } \\
(\mathrm{n}=60) \\
\text { Mean } \pm \mathrm{SD}\end{array}$ & Test for site effect & $\begin{array}{l}\text { Site effect } \\
P \text {-value }\end{array}$ \\
\hline $\operatorname{AVBT}(\mathrm{cm})$ & $1.08 \pm 0.23$ & 4.94 & normal & $1.27 \pm 0.19$ & $1.00 \pm 0.18$ & t-test & $0.00 * *$ \\
\hline SC (1-6) & $3.16 \pm 0.92$ & na & na & $2.62 \pm 0.67$ & $3.4 \pm 0.91$ & Mann-Whitney U & $0.00 * *$ \\
\hline RAM (count) & $0.68 \pm 0.84$ & na & na & $0.93 \pm 0.96$ & $0.56 \pm 0.75$ & Mann-Whitney U & 0.074 \\
\hline $\mathrm{DL}(\mathrm{Y} / \mathrm{N})$ & $0.08 \pm 0.27$ & na & na & $0.10 \pm 0.31$ & $0.07 \pm 0.25$ & $2 \times 2$ contingency table & 0.55 \\
\hline CVWS & $41.76 \pm 14097$ & 5.00 & normal & $43.30 \pm 17.87$ & $41.00 \pm 13.4$ & t-test & 0.50 \\
\hline $\operatorname{AVBRA}\left({ }^{\circ}\right)$ & $35.83 \pm 6.33$ & 4.79 & normal & $38.03 \pm 5.03$ & $34.75 \pm 6.65$ & t-test & $0.02 *$ \\
\hline AVBRD (mm) & $16.48 \pm 3.14$ & 5.85 & normal & $16.75 \pm 3.24$ & $16.35 \pm 3.10$ & t-test & 0.58 \\
\hline AVBRN (count) & $3.6 \pm 0.68$ & 4.40 & normal & $3.45 \pm 0.52$ & $3.67 \pm 0.74$ & t-test & 0.16 \\
\hline OBDBH (mm) & $16.81 \pm 2.33$ & 6.78 & normal & $17.63 \pm 2.22$ & $16.40 \pm 2.29$ & t-test & $0.02 *$ \\
\hline
\end{tabular}


Table III. Phenotypic correlations adjusted for site and plot for branching, growth, form and bark thickness traits $(\mathrm{n}=81)$. Correlations significant at the experiment-wise level of 0.05 according to Bonferroni's method, are bolded (i.e. pairwise $P$-value < 0.0006) [30]. For trait abbreviations see Methods.

\begin{tabular}{|c|c|c|c|c|c|c|c|c|c|c|c|c|c|}
\hline & AVBRN & AVBRA & RBT & $\mathrm{SC}$ & DL & RAM & AVWS & CVWS & AVBRD & HT & $\mathrm{OBDBH}$ & UBDBH & $\mathrm{BD}$ \\
\hline \multirow[t]{2}{*}{ AVBT } & -0.0145 & -0.4176 & 0.6676 & -0.0792 & -0.0513 & -0.1206 & 0.1572 & 0.0545 & 0.2708 & 0.3350 & 0.5366 & 0.3964 & 0.0326 \\
\hline & $P=0.898$ & $P=0.000$ & $P=\mathbf{0 . 0 0 0}$ & $P=0.482$ & $P=0.649$ & $P=0.284$ & $P=0.161$ & $P=0.629$ & $P=0.014$ & $P=0.002$ & $P=0.000$ & $P=0.000$ & $P=0.773$ \\
\hline \multirow[t]{2}{*}{ AVBRN } & & -0.2251 & -0.0470 & 0.2404 & 0.0314 & -0.0742 & 0.0623 & -0.0957 & -0.1878 & 0.0279 & 0.0404 & 0.0471 & 0.0906 \\
\hline & & $P=0.043$ & $P=0.677$ & $P=0.031$ & $P=0.781$ & $P=0.510$ & $P=0.581$ & $P=0.396$ & $P=0.093$ & $P=0.805$ & $P=0.720$ & $P=0.676$ & $P=0.421$ \\
\hline \multirow[t]{2}{*}{ AVBRA } & & & -0.2675 & -0.0625 & -0.0853 & -0.1094 & -0.0589 & 0.0123 & 0.1296 & -0.2448 & -0.2579 & -0.2016 & -0.1831 \\
\hline & & & $P=0.016$ & $P=0.580$ & $P=0.449$ & $P=0.331$ & $P=0.601$ & $P=0.913$ & $P=0.249$ & $P=0.028$ & $P=0.020$ & $P=0.071$ & $P=0.102$ \\
\hline \multirow[t]{2}{*}{ RBT } & & & & -0.0604 & 0.0171 & -0.1799 & 0.1323 & 0.0997 & -0.0889 & -0.1979 & -0.2600 & -0.4078 & 0.1216 \\
\hline & & & & $P=0.592$ & $P=0.879$ & $P=0.108$ & $P=0.239$ & $P=0.376$ & $P=0.430$ & $P=0.077$ & $P=0.019$ & $P=0.000$ & $P=0.280$ \\
\hline \multirow[t]{2}{*}{ SC } & & & & & 0.1229 & -0.1673 & 0.0494 & 0.0238 & -0.1519 & 0.0967 & -0.0614 & -0.0524 & 0.3026 \\
\hline & & & & & $P=0.274$ & $P=0.135$ & $P=0.661$ & $P=0.833$ & $P=0.176$ & $P=0.391$ & $P=0.586$ & $P=0.642$ & $P=0.006$ \\
\hline \multirow[t]{2}{*}{ DL } & & & & & & -0.0718 & -0.1286 & 0.0080 & -0.1996 & 0.0190 & -0.0482 & -0.0430 & -0.0762 \\
\hline & & & & & & $P=0.524$ & $P=0.252$ & $P=0.944$ & $P=0.074$ & $P=0.866$ & $P=0.669$ & $P=0.703$ & $P=0.499$ \\
\hline \multirow[t]{2}{*}{ RAM } & & & & & & & 0.2922 & -0.0196 & 0.1372 & -0.0333 & 0.0709 & 0.0995 & -0.0924 \\
\hline & & & & & & & $P=0.008$ & $P=0.862$ & $P=0.222$ & $P=0.768$ & $P=0.529$ & $P=0.377$ & $P=0.412$ \\
\hline \multirow[t]{2}{*}{ AVWS } & & & & & & & & 0.0195 & 0.5359 & 0.1753 & 0.0518 & 0.0267 & -0.0376 \\
\hline & & & & & & & & $P=0.863$ & $P=0.000$ & $P=0.117$ & $P=0.646$ & $P=0.813$ & $P=0.739$ \\
\hline \multirow[t]{2}{*}{ CVWS } & & & & & & & & & 0.0728 & 0.1303 & -0.0427 & -0.0572 & -0.0146 \\
\hline & & & & & & & & & $P=0.518$ & $P=0.246$ & $P=0.705$ & $P=0.612$ & $P=0.897$ \\
\hline \multirow[t]{2}{*}{ AVBRD } & & & & & & & & & & 0.1910 & 0.4430 & 0.4311 & -0.1470 \\
\hline & & & & & & & & & & $P=0.088$ & $P=0.000$ & $P=0.000$ & $P=0.190$ \\
\hline \multirow[t]{2}{*}{ HT } & & & & & & & & & & & 0.6529 & 0.6474 & 0.0718 \\
\hline & & & & & & & & & & & $P=0.000$ & $P=0.000$ & $P=0.524$ \\
\hline \multirow[t]{2}{*}{ OBDBH } & & & & & & & & & & & & 0.9874 & -0.0887 \\
\hline & & & & & & & & & & & & $P=0.000$ & $P=0.431$ \\
\hline \multirow[t]{2}{*}{ UBDBH } & & & & & & & & & & & & & -0.1012 \\
\hline & & & & & & & & & & & & & $P=0.368$ \\
\hline
\end{tabular}

Ten putative QTL were identified for branching traits. All putative QTL for branching traits had low to moderate (0.19-0.81) standardised gene effects $\left(\Delta_{1}\right)$, i.e. the difference in standard deviation units between the two genotypic classes [13]. Two putative QTL for AVWS were identified from the male parent, $\mathrm{PCH}$ (table IV). The putative QTL were located on separate linkage groups, 14 and 23 and explained $15 \%$ and $19 \%$ of the genetic variance respectively. The putative QTL were of opposite effect i.e. inheritance of the putative QTL caused the trait to increase at one locus and decrease at the other. The $\Delta_{1}$ for each putative QTL was 0.54 and 0.60 . The difference between the family mean and the genotype with the favorable allele $\left(\Delta_{2}\right)$, assuming a wider whorl spacing is favorable, was 0.29 for each locus. The AVWS variable had several outliers, individuals with very high whorl spacing. These outliers contributed to a high $\mathrm{S}$ test statistic for these putative QTL due to a poor fit of residuals. To examine whether these outliers disproportionately contributed to the significance of the putative QTL, the outlier values were changed to missing data points and the variable was reanalysed (data not shown). Putative QTL remained significant without outlier data, hence, the analysis including the outliers is presented.

Three putative QTL were detected for AVBRNO, one from the male and two from the female parent. Two putative QTL for AVBRD were also detected from the female parent. The two putative QTL for branch diameter increased branch diameter when the QTL allele was inherited and combined, the putative QTL contributed to $33 \%$ of genotypic variation, assuming additivity of effects. These two putative QTL peaks were located nearby $(\sim 8 \mathrm{cM})$ on the same linkage group and may represent a single QTL as the analysis probably does not allow enough resolution to detect more than one QTL in this region. A single putative QTL for CVWS was identified on the female map linked to the locus a09_154A. This putative QTL allele accounted for $17 \%$ of the genotypic variation and tended to reduce variation in whorl spacing.

Putative QTL detected for AVBT, HT, UBDBH, OBDBH and $\mathrm{BD}$ were also detected and their effects are summarised in table IV. No putative QTL for detected for the variable RBT. 
Table IV. QTL detected by composite interval mapping with site co-variate in QTLCartogarpher. QTL significant at experiment-wise error level of 0.05 determined from 1000 permutations.

\begin{tabular}{|c|c|c|c|c|c|c|c|c|c|c|c|c|c|c|c|c|c|c|c|}
\hline ait $^{1}$ & & & & $\begin{array}{l}\text { osi- } \\
\text { on }^{4}\end{array}$ & & & & $\begin{array}{l}\text { EW } \\
0.05^{7}\end{array}$ & $\begin{array}{l}\text { EW } \\
0.01^{7}\end{array}$ & $\mathrm{dd}^{6}$ & $22^{6}$ & & $S^{6}$ & $\begin{array}{l}\mathrm{Het}^{8} \\
\text { (mean) }\end{array}$ & $\begin{array}{l}\text { Het } \\
\text { (SD) }\end{array}$ & $\begin{array}{l}\text { Hom }^{8} \\
\text { (mean) }\end{array}$ & $\begin{array}{l}\text { Hom } \\
\text { (SD) }\end{array}$ & $\begin{array}{l}\text { Delta } \\
1^{9}\end{array}$ & $\begin{array}{l}\text { Delta } \\
2^{9}\end{array}$ \\
\hline & & 7 & & & off end & & & & & & & & & & & & 0.24 & 0.61 & 0.26 \\
\hline & M & & & & & & & & & & & & & & & & & & .09 \\
\hline VWS & M & 14 & $3 \mathrm{~A}$ & 38.99 & 422 & 3.99 & & 13.00 & 7.24 & & & 46 & & & & & 13 & & .29 \\
\hline NS & M & 23 & a04r165C & 47.37 & 38.33 & 53.37 & 22.72 & 13.00 & 17.24 & -26.62 & 0.19 & 0.43 & 127.94 & 74.26 & 33.54 & & 7.80 & 0.60 & 0.29 \\
\hline VBRN & M & 24 & 19_147A & 42.01 & 32.01 & 53.01 & .65 & 12.85 & 6.61 & & 0.1 & 8 & & & & & & 0 & .28 \\
\hline $\mathrm{T}$ & M & 24 & $3 \mathrm{~A}$ & 0.01 & ad & 0.01 & 0.31 & 12.92 & 15.73 & 0.8 & 0 . & 0 & & & & & & & 0.21 \\
\hline BD & M & 20 & & & & & & & & & & & & & & & & & \\
\hline & $\mathrm{F}$ & 1 & & & & & & & & & & & & & & & & & 0.46 \\
\hline & F & & & & & & & & & & & & & & & & & & \\
\hline UBDBH & $\mathrm{F}$ & 14 & a03_142B & 4.01 & off end & 18.01 & 16.97 & 12.18 & 16.83 & 1.59 & 0.17 & 0.38 & 0.12 & 14.01 & 1.96 & 15.56 & 1.41 & 0.73 & 0.44 \\
\hline
\end{tabular}

${ }^{1}$ Trait abbreviations - see Methods.

${ }^{2}$ Parent $-\mathrm{M}=$ male parent $P$. caribaea var. hondurensis; $\mathrm{F}=$ female parent $P$. elliottii var. elliottii.

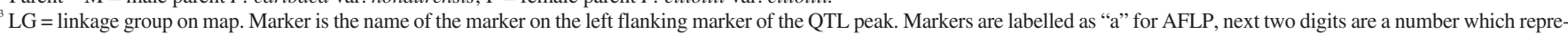

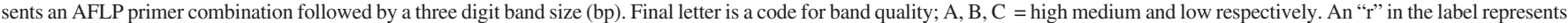
marker linked in reverse phase to the one in which it was scored.

${ }^{4}$ Position = distance in $\mathrm{cM}(\mathrm{K})$ from the left telomere.

${ }^{5} \mathrm{CIL} \& \mathrm{CIR}=1 \mathrm{LOD}$ confidence limit on peak position left and right boundaries.

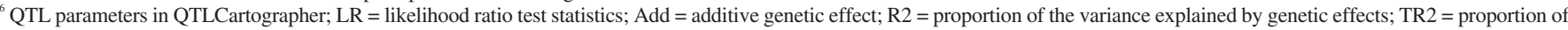
the total variance explained by the model ie includes convariates; $\mathrm{S}=$ test statistic $\mathrm{S}$ for normality of the residuals under $\mathrm{H}_{1}$ [2].

${ }^{7}$ EW $0.05 \&$ EW0.01 are the experiment-wise log likelihood thresholds at the $\alpha=0.05$ and 0.01 levels determined from 1000 permutations in QTLCartographer [8].

${ }^{8}$ Genotype means for heterozgyotes (Het) and homozygotes (Hom) determined from independent t-tests at the marker.

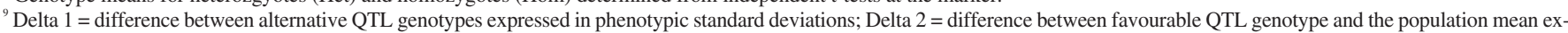
pressed in phenotypic standard deviations [13]

\subsection{Single Marker Tests}

No putative QTL were detected for SC, DL or RAM using single marker tests.

\section{DISCUSSION}

Exploiting within family variation generated from the crossing of two heterozygous parents, putative QTL influencing branch characteristics, bark thickness, growth and wood density have been mapped in a $\mathrm{PEE} \times \mathrm{PCH}$ hybrid. Branching characters exhibited considerable variation in the family but were typically 1-2 SD less variable than growth traits. Despite lower variances, evidence of genetic control was found in all branching traits except AVBRA. One or two putative QTL of moderate additive effect $\left(\mathrm{r}^{2}=0.1-0.2\right)$ were identified for most traits with no evidence of additive $\times$ additive epistasis or pleiotropy. Branching characters were generally not influenced by the environment and were largely independent of each other, growth and wood density traits.

Several aspects of the genetic models that are emerging for branching traits required closer evaluation and reconciling with our expectations of the mode of inheritance and importance of the environment in explaining variability. The design of a QTL detection experiment determines the power to detect QTL as well as the accuracy and precision of the estimates [4]. Small sample sizes can be a major limitation on the power to detect small effect QTL and frequently estimates of their magnitude are overestimated. For example, using simulation analysis on a population of 100 F2 progeny, Beavis estimated that when there was 10 QTL per trait explaining $63 \%$ of the phenotypic variability and no dominance, the power to detect QTL was only 33\%. This declined to $9 \%$ when 10 QTL accounted for $30 \%$ of the phenotypic variation. Furthermore, the estimates of variance explained tended to be inflated, av. $16.76 \% \pm 0.40$ when the true value was av. 3\%. Hence the power for detection of small effect QTL in our experiment could be quite low as backcross designs have approximately half the power of $\mathrm{F}_{2}$ [36]. If these power and accuracy limitations were applicable to our experiment, the model of genetic control would be significantly different, indicating the traits are controlled by substantially more genes than we have detected and of smaller effect. 
Despite these limitations for detecting small gene effects, our experimental design should provided adequate power for detecting large, additive gene effects. Simulations of a single QTL per genome with $\mathrm{h}^{2}=0.5$ and no dominance on our male map using QTLCartographer, for example, indicated all QTL were detected by CIM for a 100 replicates where an experiment-wise $\alpha$ of 0.05 was applied (data not shown). The power declined to $87 \%$ when the $\mathrm{h}^{2}$ of simulated QTL was reduced to 0.2. Nonetheless, there was no evidence of large gene effects for branching traits either from the QTL study or from multi-modality in frequency distributions. Large gene effects may be more evident in advanced generation hybrids or where there has been inbreeding. Given the lack of evidence for any large effect genes, we conclude that we are probably detecting small effect genes that are overestimated as a consequence of limitations of the experimental design.

A general absence of environmental effects in branching characters is somewhat at odds with previous quantitative studies of the genetics of branching in pines. This may be an indication of the importance of dominance, genotype $\times$ environmental $(\mathrm{G} \times \mathrm{E})$ factors or other nonallelic interactions in explaining the variation in our hybrid family. Our use of markers segregating in a testcross configuration did not allow us to test for dominance effects in this study, so we could not distinguish between dominance, epistatic (other than $\mathrm{A} \times \mathrm{A}$ ) and $G \times E$. In summary, therefore, a working model for the genetic architecture of branching traits in hybrid pines is that these traits are controlled by small effect genes with additive gene action, but that dominance or nonallelic interactions may be important in the expression of some traits.

Branching architecture traits were largely uncorrelated amongst themselves and with other traits, which suggested they would not be greatly affected by selection for growth, form or wood density. A drawback, however, to the lack of inter-correlation amongst branching traits is that selection would need to occur simultaneously on a range of traits. An exception to this lack of correlation was AVBRD and OBDBH. Branch diameter has been found to be positively, hence, adversely correlated with tree vigour (girth and/or height) in at least three studies in pines $[6,23,35]$. This may mean that in selecting for trees on the basis of vigour there will also indirectly select for heavier branching. The lack of co-localization of QTL for these traits, however, suggests that different genome regions influence these traits and that there is potential to break this correlation.

Phenotypic correlation from the current study also indicated that AVBRD had a moderate positive correlation with AVWS. This correlation may result from resource allocation in the tree. A tree laying down thicker, and presumably longer and more productive branches may not need as many whorls (branch diameter and length are positively correlated in pines $[6,22])$ or vice versa. Again, however, as AVBRD and AVWS appear uncorrelated at the genetic level, selection for lighter branching may occur independent of selection for whorl spacing.
Failure to identify any QTL for AVBRA was surprising given it tends to be amongst the more heritable (0.3-0.4) branching traits in pines $[22,23]$. Possible explanations include; a lack of segregation for genes controlling this trait in this family, incomplete map coverage, low power to detect QTL or differences in the way the trait was assessed compared with other studies. Most studies only measure branch angle on one or two whorls per tree whereas we measured 6 whorls typically. Branch angle tends to vary along the trunk and between major and minor whorls in pines [12]. An equilibrium zone, where branch angle is stabilised, has been recognised in pines and other trees and it has been suggested to characterise the branch angle of a tree, and that whorls should be sampled in this region (references within [12]). It may be important to account for patterns of within tree variation to identify QTL for branch angle and reanalysis of selective branch angle data may be valuable.

The largest branching architecture QTL in the study was detected for CVWS. Regularity of whorl spacing may represent the best prospect for tree improvement of branching characteristics in this family. Regularity of whorl spacing is a consequence of the growth patterns of a tree. PEE has a defined dormancy period and lays down a heavy whorl during vigorous growth at the beginning of the season [35]. This is followed by clusters of subsidiary whorls of lighter branches that develop later in the season. The number of whorls is related to the length of the growth season utilised by the tree. Growth season length tends to be variable in slash pine [35]. Caribbean pine on the other hand, has no defined dormant period and grows throughout the year. Consequently, clear differences in branching patterns are evident between the parental species. PEE tends to have clusters of branch whorls and more irregular whorl spacing compared with a more regular spacing in $\mathrm{PCH}$ [9]. The objective for a breeding program may be to select for longer lengths of clear wood, hence, trees with larger CVWS may be more valuable.

\section{CONCLUSIONS AND FUTURE WORK}

The power of our experiment to detect QTL was limited by the small sample size. Low power may lead to undetected QTL and hence genetic models that are over simplified. Where the power of a QTL detection experiment is low, there is a bias toward detection of QTL of large effect and small effects tend to be overestimated $[4,17,18]$. Furthermore, the detection of spurious QTL increases with small populations due to sampling bias [7] and estimates of QTL parameters may be biased by non-simultaneous estimation methods [18]. These factors indicate that until further analysis can be conducted on a large sample, the models for branching characters should only be considered preliminary and a first glimpse of the genetics of branching architecture in hybrid pines.

The small amounts of additive genetic control identified for most branching traits suggests they will be amongst the 
more difficult to improve in hybrid pines. The importance of dominance and nonallelic interactions in controlling these traits is yet to be determined but may be significant as the traits are largely unaffected by the environment. Large scale QTL detection experiments will be required to develop accurate and reliable genetic models as gene effects for branching traits appear to be small. Other families will need to be examined to determine if variation in branching traits are inherently less than growth variables, as detected for the family in this study. Prospects for a rationalisation of the number of branching variables are low due to the apparent lack of redundancy amongst branching and other traits. One way to reduce the high costs of the intensive measurements required for branching may be to reduce the number of whorls assessed, however, care is required to retain repeatability of measures due to the high within tree variation in most branching traits [22]. The surprisingly low influence of environment on most branching traits suggests replication over sites can be minimised.

Acknowledgments: The authors thank Mr. P. Toon for assistance with collection of foliage samples and measurement data, Dr. K. Harding, Mr. T. Copley, Mr. P. Toon, Mr. G. Hughes, Ms. S. Roberts and Mr. A. Cause for collecting wood cores, Dr. C. Matherson and Mr. D. Kain for wood density analysis. We also thank Dr. S. Carson for many helpful discussions, Drs. G. Dale, K. Harding, B. Potts and two anonymous reviewers for valuable comments on earlier manuscripts, and Dr. R. Vaillancourt for providing a French translation of the abstract.

\section{REFERENCES}

[1] Aravanopoulous F.A., Doulis A., Harfouche A., Ghosn D.R., Molecular breeding of crown and branch quantitative traits in cypress (Cupressus sempervirens L.), in: Conference IUFRO Wood Breeding and Biotechnology, June 11-14, 2001, Bordeaux (unpublished).

[2] Basten C.J., Weir B.S., Zeng Z.-B., QTL Cartographer V1.13. A reference manual and tutorial for QTL mapping, Department of Statistics, North Carolina State University, 1999.

[3] Basten C.J., Weir B.S., Zeng Z.B., Zmap-a QTL cartographer, 5th World Congress on Genetics Applied to Livestock Production, 1994, pp. 65-66.

[4] Beavis W.D., QTL analysis: power, precision, and accuracy, in: Paterson A.H. (Ed.), Molecular Dissection of Complex Traits, CRC Press, Boca Raton, 1998, pp. 145-162.

[5] Bradshaw H.D.J., Stettler R.F., Molecular genetics of growth and development in Populus. IV: Mapping QTLs with large effects on growth, form and phenology traits in a forest tree, Genetics 139 (1995) 963-973.

[6] Brown A.G., Doran J.C., Variation in growth and branching characteristics of Pinus attenuata, Silvae Genet. 34 (1985) 100-104.

[7] Carson S., Djorovic N., Djorovic A., Wilcox P., Ball R., Simulation of QTL detection and MAS I: impact of population size, underlying genetic structure, and methods of choosing markers, Genetics (to appear).

[8] Churchill G.A., Doerge R.W., Empirical threshold values for quantitative trait mapping, Genetics 142 (1994) 285-294.

[9] Dale G., Genetic mapping in an interspecific hybrid between Pinus caribaea and Pinus elliottii, Ph.D., University of Queensland, 1994.

[10] Dieters M.J., Genetic parameters for slash pine (Pinus elliottii) grown in south-east Queensland, Australia: Growth, stem straightness and crown defects, For. Genet. 3 (1996) 27-36.
[11] Dixon R., Physiological processes and tree growth, in: Dixon R., Meldahl R., Ruark G., Warren W. (Eds.), Process modelling of forest growth responses to environmental stress, Timber Press, Portland Oregon, 1990, pp. 21-32.

[12] Franklin E.C., Callaham R.Z., Multinodality, branching and forking in lodgepole pine (Pinus contorta var. murrayana Engelm.), Silvae Genet. 19 (1970) 180-184.

[13] Grattapaglia D., Bertolucci F.L., Sederoff R.R., Genetic mapping of QTLs controlling vegetative propagation in Eucalyptus grandis and E. urophylla using a pseudo-testcross strategy and RAPD Markers, Theor. Appl. Genet. 90 (1995) 933-947.

[14] Grattapaglia D., Bertolucci F.L.G., Penchel R., Sederoff R., Genetic mapping of quantitative trait loci controlling growth and wood quality traits in Eucalyptus grandis using a maternal half-sib family and RAPD markers, Genetics 144 (1996) 1205-1214.

[15] Grattapaglia D., Sederoff R., Genetic linkage maps of Eucalyptus grandis and Eucalyptus urophylla using a pseudo-testcross mapping strategy and RAPD markers, Genetics 137 (1994) 1121-1137.

[16] Haines R.J., Clonal forestry in Queensland and implications for hybrid breeding strategies, Proceedings of QFRI/CRC-SPF Symposium, Hybrid Breeding and Genetics of Forest Trees, April 9-14th, 2000, Noosa, Queensland, Australia, 2000, pp. 386-389.

[17] Kearsey M.J., Farquhar G.L., QTL analysis in plants: where are we now?, Heredity 80 (1998) 137-142.

[18] Knapp S., Bridges W.C., Liu B.H., Mapping quantitative trait loci using nonsimultaneous and simultaneous estimations and hypothesis tests, in: Beckmann J. S., Osborn T.C. (Eds.), Plant genomes: methods for genetic and physical mapping, 1st ed., Kluwer Academic Publishers, The Netherlands, 1992, Vol. 1, pp. 209-237.

[19] Kubisiak T.L., Nelson C.D., Nance W.L., Stine M., RAPD linkage mapping in a longleaf pine $\times$ slash pine F1 family, Theor. Appl. Genet. 90 (1995) 1119-1127.

[20] Lander E., Green P., Abrahamson J., Barlow A., Daley M.J., Lincoln S.E., Newburg L., MAPMAKER: An interactive computer package for constructing primary genetic linkage maps of experimental and natural populations, Genomics 1 (1987) 174-181.

[21] Lincoln S.E., Daly M.J., Lander E.S., Mapping genes controlling quantitative traits using MAPMAKER/QTL version 1.1: A Tutorial and Reference Manual, 1993.

[22] Magnussen S., Yeatman C.W., Early testing of jack pine, Can. J. For. Res. 17 (1987) 460-465.

[23] Merrill R.E., Mohn C.A., Heritability and genetic correlations for stem diameter and branch characteristics in white spruce, Can. J. For. Res. 15 (1985) 494-497.

[24] Nikles D.G., The first 50 years of the evolution of forest tree improvement in Queensland, QFRI-IUFRO Conference "Tree improvement for sustainable forestry", Caloundra, Queensland, Australia, 1996, pp. 51-64.

[25] Paterson A., Lin Y.-R., Li Z., Schertz K., Doebley J., Pinson S., Liu S.-C., Stansel J., Irvine J., Convergent domestication of cereal crops by independent mutations at corresponding genetic loci, Science 269 (1995) 1714.

[26] Plomion C., Yani A., Marpeau A., Genetic determinism of delta3-carene in maritime pine using random amplified polymorphic DNA (RAPD) markers, Genome 39 (1996) 1123-1127.

[27] Potts B.M., Barbour R.C., Hingston A.B., Genetic pollution from farm forestry, RIDC, 2001.

[28] Powell M.B., Nikles D.G., Performance of Pinus elliottii var. elliottii and P. caribaea var. hondurensis and their F1, F2 and backcross hybrids across a range of sites in Queensland, QFRI-IUFRO Conference "Tree improvement for sustainable forestry", Caloundra, Queensland, Australia, 1996, pp. 382-383.

[29] Remington D.L., Whetten R.W., Liu B.H., O’Malley D.M., Construction of an AFLP genetic map with nearly complete genome coverage in Pinus taeda, Theor. Appl. Genet. 98 (1999) 1279-1292.

[30] Rice W.R., Analysing tables of statistical tests, Evolution 43 (1989) 223-225. 
[31] Graham G.C., Mayers P., Henry R.J., A simplified method for the preparation of fungal genomic DNA for PCR and RAPD analysis, Biotechniques 16 (1994) 48-50.

[32] Shepherd M., Chaparro J.X., Teasdale R., Genetic mapping of monoterpene composition in an interspecific eucalypt hybrid, Theor. Appl. Genet. 99 (1999) 1207-1215.

[33] Shepherd M., Cross M., Dieters M.J., Williams C.G., Henry R.J., Genetic linkage maps for a select individuals from Pinus elliottii var. elliottii and P. caribaea var. hondurensis using AFLP and microsatellite markers, Theor. Appl. Genet. (to appear).

[34] Shepherd M., Cross M., Maguire T., Dieters M., Williams C., Henry R., Transpecific microsatellites for hard pines, Theor. Appl. Genet., 104 (2002) 819-827.

[35] Slee M.U., Growth patterns of slash and Caribbean pine and their hybrids in Queensland, Euphytica 21 (1972) 129-142.
[36] Soller M., Genizi A., Brody T., On the power of experimental designs for the detection of linkage between marker loci and quantitative loci in crosses between inbred lines, Theor. Appl. Genet. 47 (1976) 35-39.

[37] Toon P.G., Dieters M.J., Nikles D.G., Components of a slash pine (Pinus elliottii var. elliottii) breeding strategy for the continued improvement of its hybrids, QFRI-IUFRO Conference "Tree improvement for sustainable forestry", Caloundra, Queensland, Australia, 1996, pp. 388-390.

[38] Wu R., Li B., A multiplicative-epistatic model for analyzing interspecific differences in outcrossing species, Biometrics 55 (1999) 355-365.

[39] Wu R.L., Quantitative genetics of yield breeding for Populus short-rotation culture, Can. J. For. Res. 24 (1994) 155-165.

[40] Zar J.H., The normal distribution, in: Biostatistical Analysis, 2nd ed., Prentice Hall International Editions, 1984, Vol. 1, pp. 79-96.

[41] Zobel B., Talbert J., Applied forest tree improvement, John Wiley \& Sons, New York, 1984.

[42] Zobel B.J., Jett J.B., Genetics of wood production, 1st ed., Springer, 1996.

To access this journal online: www.edpsciences.org 
